International Journal of

\title{
The Effects of Life-sustaining Treatment Preferences on Geriatric Depression: Centered on the Mediating Effects of Ego Integrity and Social Support
}

\author{
First S. H. Kim', Second O. S. Cho ${ }^{2}$ \\ ${ }^{1}$ Vice Chairman of the Asiana Social Welfare Foundation Social Cooperative, ${ }^{2}$ Lecturer Professor, Graduate School of \\ Social Welfare Administraion, University of Hansei, Korea
}

\begin{abstract}
Background/Objectives The purpose of this study was to understand the effects of the preference levels of the elderly for life-sustaining treatment on their depression and to analyze the mediating effects of ego integrity and social support as positive factors within the relationship between life-sustaining treatment preference and geriatric depression. Methods/Statistical analysis: The collected data was cleaned by a data coding process and executed data analyses such as descriptive statistical analysis, correlation analysis, and stepwise regression analysis by the SPSS WIN21.0 program. The Sobel test was used for verification of the mediation effects of ego integrity and social support. Findings: As a result of the verification of the mediation effect of ego integrity on the relationship between the elderly's preference for life-sustaining treatment and depression, ego integrity $(p<.05)$ is indicated as statistically significant, thus explained as a complete mediation effect. As a result of verifying the mediation effect of social support on the relationship between the elderly's preference levels for life-sustaining treatment and depression, social support displays a statistically significant $(p<.05)$, thus explained as a complete mediation effect. Improvements/Applications: It is highly recommended that each senior welfare center and senior centers operate an ego integration program designed to recollect all stages of their past life at senescence and to be able to organize tasks to be achieved on each developmental stage. This study is meaningful and useful because there are not many studies on the relationship between lifesustaining treatment preference and depression in social welfare academia.
\end{abstract}

Index Terms

The elderly, life-sustaining treatment preference, depression, ego integrity, social support

Corresponding author: O.S. Cho

Sun16070r@naver.com

- Manuscript received January 15, 2021.

- Revised February 10, 2021 ; Accepted March 1, 2021.

- Date of publication March 30, 2021.

(C) The Academic Society of Convergence Science Inc.

2619-8363 C 2021 IJBSA. Personal use is permitted, but republication/redistribution requires IJBSA permission. 


\section{Introduction}

The average life expectancy of the elderly has increased due to the development of modern medicine and the improvement of social living environment. Accordingly, the elderly population is rapidly increasing. As the elderly population increases at the fastest pace among OECD countries, the elderly problem is becoming a social problem in South Korea. The purpose of this study is to investigate the actual condition of the elderly population aged 65 and over in South Korea and to identify the factors that affect the depression of the elderly population. In particular, this study analyzes and discusses the relationship between ego integration, social support, life-sustaining treatment preference, and depression. Based on the above research objectives, the following specific research questions are raised.

[Research Question 1] How does the preference of lifesustaining treatment affect depression in the elderly? [Research Question 2] Does ego integrity mediate the effects of life-sustaining treatment preference on depression in the elderly?

[Research Question 3] Does social support mediate the effects of life-sustaining treatment preference on depression in the elderly?

\section{I.Research Methor}

In this study, the relationship between the independent variable and the dependent variable is shown.

\section{II.Hypotheis Setting}

$<$ Hypothesis $1>$ The more the elderly do not prefer lifesustaining treatment, the lower the depression will be.

$<$ Hypothesis $2>$ The elderly's ego integrity will mediate the effects of the elderly's preference for life-sustaining treatment on depression.

$<$ Hypothesis3 $>$

Social support will mediate the effects of the elderly's preference for life-sustaining treatment on depression.

\section{III.Analysis Method}

This study used SPSS WIN 21.0 program to explain the characteristics, correlations, step-by-step influences, and mediating effects of variables related to depression of the elderly. Regression analysis was used to analyze the causal relationship between the elderly's life-sustaining treatment preference, ego integrity, social support and depression. In addition, Sobel test was conducted to verify the mediating effect.

\section{IV.Results}

\section{V.Figures and Tables}

\section{1) The Mediating Effects of Ego Integrity on the} Influence of Elderly's Preference for Lifesustaining Treatment on Depression.

To find out whether ego integrity mediates the effects of life sustaining treatment on depression in the elderly, this study verified the mediating effects based on the mediation analysis of Baron and Kenny(1986) as shown in <Table $1>$. In the first stage, the elderly's preference for life-sustaining treatment $(\beta=.137, \quad \mathrm{p}<.01) \quad$ was statistically significant and positively $(+)$ affected by ego integrity, and the independent variable's explanatory power on ego integrity as a parameter was $1.9 \%$. In the second stage, the preference of life-sustaining treatment of the elderly, an independent variable, had a statistically significant negative(-) effect on depression, a dependent variable $(\beta=-.110, p<.05)$. In the third stage, depression, which is a dependent variable, was analyzed by substituting the elderly's preference for life-sustaining treatment, an independent variable, and the ego integrity, a mediating variable. The results of the analysis showed that the preference for life-sustaining treatment of the elderly, which is an independent variable of the first stage, did not show statistically significant influence in the third stage $(\beta=-.042, t=-.921)$. Also, the ego integrity of the elderly was verified to have negative (-) effects on depression $(\beta=-.494, p<.001)$. In other words, the more the elderly actively oppose the preference for life-sustaining treatment, the better the ego integrity is. This means that depression is lowered if the ego integrity is achieved well. This means that ego integrity fully mediates the relationship between the elderly's preference for life-sustaining treatment and depression. In the third stage, the independent variable's explanatory power on depression, which is a dependent variable, was $25.1 \%$.

Table 1. Effects of the elderly's sense of ego-integration

\begin{tabular}{ccccccccc}
\hline Le & variable & $\mathrm{B}$ & & $\beta$ & $\mathrm{t}$ & $\mathrm{F}$ & $\mathrm{R}^{2}$ & $\mathrm{adj}$. \\
vel & & & & & & & & \\
\hline
\end{tabular}


The Effects of Life-sustaining Treatment Preferences on Geriatric Depression: Centered on the Mediating Effects of Ego Integrity and Social Support

\begin{tabular}{|c|c|c|c|c|c|c|c|}
\hline 1 & $\begin{array}{c}\text { life- } \\
\text { sustaining } \\
\text { treatment } \\
\text { preference } \\
\rightarrow \text { ego } \\
\text { integrity }\end{array}$ & $\begin{array}{c}.096 \\
* *\end{array}$ & .137 & 2.632 & $\begin{array}{c}6.927 \\
* *\end{array}$ & .019 & .016 \\
\hline 2 & $\begin{array}{c}\text { life- } \\
\text { sustaining } \\
\text { treatment } \\
\text { preference } \\
\rightarrow \\
\text { depressio } \\
\mathrm{n}\end{array}$ & $\begin{array}{c}-.073 \\
*\end{array}$ & -.110 & $\begin{array}{c}- \\
2.105\end{array}$ & $\begin{array}{c}4.432 \\
*\end{array}$ & .012 & .009 \\
\hline 3 & $\begin{array}{c}\text { life- } \\
\text { sustaining } \\
\text { treatment } \\
\text { preference } \\
+ \\
\text { ego } \\
\text { integrity } \\
\rightarrow \\
\text { depressio } \\
n\end{array}$ & $\begin{array}{c}-.464 \\
* * *\end{array}$ & -.494 & $\begin{array}{c}- \\
10.72 \\
1\end{array}$ & $\begin{array}{c}60.38 \\
2 \\
* * *\end{array}$ & .251 & .247 \\
\hline
\end{tabular}

$* \mathrm{p}<.05, * * \mathrm{p}<.01, * * * \mathrm{p}<.001$

\section{2)The Mediating Effects of Social Support on the Influence of Elderly's Preference for Life- sustaining Treatment on Depression}

In the first stage, the elderly's preference for lifesustaining treatment $(\beta=.170, \quad \mathrm{p}<.01)$ had a statistically significant and positive $(+)$ effect on social support, and the independent variable's explanatory power on social support as a parameter was $2.7 \%$. In the second stage, the preference of life-sustaining treatment of the elderly, an independent variable, had a statistically significant negative (-) effect on depression, a dependent variable $(\beta=-.110, p<.05)$. In the third stage, depression, which is a dependent variable, was analyzed by substituting the elderly's preference for life-sustaining treatment, an independent variable, and social support, a mediating variable. The results of the analysis showed that the preference for life-sustaining treatment of the elderly, which is an independent variable of the first stage, did not show statistically significant influence in the third stage $(\beta=-.054, t=-1.073)$. Also, social support of the elderly was verified to have negative (-) effects on depression $(\beta=-.346 \mathrm{p}<.001)$. In other words, the more the elderly do not prefer life-sustaining treatment, the higher social support, and the higher social support, the lower depression. In the process of verifying the mediating effect of Baron and Kenny, the independent variable, which is the second stage analysis result, is significant in the effect on the dependent variable, and In the third stage test, if the independent variable has no significant effect on the dependent variable, it is explained that it has a complete mediating effect. Therefore, it means that social support fully mediates the relationship between the elderly's preference for life-sustaining treatment and depression. In the third stage, the independent variable's explanatory power on depression, which is a dependent variable, was $12.9 \%$.

Table 2. Mediated effect verification

\begin{tabular}{|c|c|c|c|c|c|c|c|}
\hline $\begin{array}{l}\text { Le } \\
\text { vel }\end{array}$ & variable & B & $\beta$ & $\mathrm{t}$ & $\mathrm{F}$ & $\mathrm{R}^{2}$ & $\begin{array}{l}\text { adj. } \\
\mathrm{R}^{2}\end{array}$ \\
\hline 1 & $\begin{array}{c}\text { life- } \\
\text { sustaining } \\
\text { treatment } \\
\text { preference } \\
\rightarrow \text { social } \\
\text { support }\end{array}$ & $\begin{array}{l}.170 \\
* *\end{array}$ & .164 & 3.150 & $\begin{array}{c}9.922 \\
* *\end{array}$ & $\begin{array}{c}.02 \\
7\end{array}$ & $\begin{array}{c}.02 \\
4\end{array}$ \\
\hline 2 & $\begin{array}{c}\text { life- } \\
\text { sustaining } \\
\text { treatment } \\
\text { preference } \\
\quad \rightarrow \\
\text { depression }\end{array}$ & $\begin{array}{c}-.073 \\
*\end{array}$ & $\begin{array}{c}- \\
.110\end{array}$ & -2.105 & $\begin{array}{l}4.432 \\
*\end{array}$ & $\begin{array}{c}.01 \\
2\end{array}$ & $\begin{array}{c}.00 \\
9\end{array}$ \\
\hline 3 & $\begin{array}{c}\text { life- } \\
\text { sustaining } \\
\text { treatment } \\
\text { preference + } \\
\text { social } \\
\text { support } \rightarrow \\
\text { depression }\end{array}$ & $\begin{array}{l}-.219 \\
* * *\end{array}$ & $\begin{array}{c}- \\
.054\end{array}$ & -6.940 & $\begin{array}{c}26.584 \\
* * *\end{array}$ & $\begin{array}{c}.12 \\
9\end{array}$ & $\begin{array}{c}.12 \\
4\end{array}$ \\
\hline
\end{tabular}

${ }^{*} \mathrm{p}<.05,{ }^{* *} \mathrm{p}<.01, * * * \mathrm{p}<.001$ 


\section{3) Effect Decomposition}

The research model is shown as $<$ Table $3>$ in depth by disassembling the path to depression through the medium of ego integrity of elderly people's preference for life-sustaining treatment. The verification of effect decomposition was analyzed by Sobel test, and the elderly's preference for lifesustaining treatment was shown to have direct effect on ego integrity $(\beta=.137, p<.01)$, which showed statistically significant effect. In addition, the direct effect ( $\beta=-.499, p<.001)$ was statistically significant in the effect of ego integrity on depression. The elderly's preference for life-sustaining treatment was statistically significant in direct effect $(ß=-.110$, $\mathrm{p}<.05)$ and indirect effect $(\beta=-.068, \mathrm{p}<.05)$ on depression, and the total effect $(B=-.178)$ was also statistically significant. The elderly's preference for life-sustaining treatment showed direct effect $(B=.164, p<.01)$ on the influence on social support, which was statistically significant. In the effect of social support on depression, direct effect ( $B=-.355$, $\mathrm{p}<.001)$ was statistically significant. The elderly's preference for life-sustaining treatment was statistically significant in the direct effect $(B=-.110$, $\mathrm{p}<.05)$, indirect effect $(B=-.058, \mathrm{p}<.01)$, and total effect $(B=.168)$ on the influence of depression. The results of the Sobel test in order to examine the mediating effect significance of social support and ego integrity were statistically significant $<$ Table $4>$.

Table 3. Mediated effect verification

\begin{tabular}{|c|c|c|c|c|c|}
\hline & path & & $\begin{array}{l}\text { Direct } \\
\text { effects }\end{array}$ & $\begin{array}{c}\text { indir } \\
\text { ect } \\
\text { effec } \\
\text { ts }\end{array}$ & $\begin{array}{l}\text { Total } \\
\text { effects }\end{array}$ \\
\hline $\begin{array}{c}\text { life- } \\
\text { sustainin } \\
\mathrm{g} \\
\text { treatment } \\
\text { preferenc } \\
\text { e }\end{array}$ & $\begin{array}{c}\square \text { ego } \\
\text { integrity }\end{array}$ & & $\begin{array}{c}.137 \\
* *\end{array}$ & & .137 \\
\hline & $\begin{array}{c}\text { ego integrity } \\
\square\end{array}$ & $\begin{array}{l}\text { depre } \\
\text { ssion }\end{array}$ & $\begin{array}{l}-.499 \\
* * *\end{array}$ & & -.499 \\
\hline
\end{tabular}

\begin{tabular}{|c|c|c|c|c|c|}
\hline $\begin{array}{l}\text { life- } \\
\text { sustainin } \\
\quad \mathrm{g} \\
\text { treatment } \\
\text { preferenc } \\
\mathrm{e}\end{array}$ & $\begin{array}{c}\square \text { ego } \\
\text { integrity }\end{array}$ & $\begin{array}{c}\square \\
\text { depre } \\
\text { ssion }\end{array}$ & $\begin{array}{l}-.110 \\
*\end{array}$ & $\begin{array}{c}- \\
.068 \\
*\end{array}$ & -.178 \\
\hline \multirow[t]{2}{*}{$\begin{array}{c}\mathrm{g} \\
\text { treatment } \\
\text { preferenc } \\
\mathrm{e}\end{array}$} & $\begin{array}{l}\square \text { social } \\
\text { support }\end{array}$ & & $\begin{array}{l}.164 \\
* *\end{array}$ & & .164 \\
\hline & $\begin{array}{c}\text { social } \\
\text { support } \square\end{array}$ & $\begin{array}{l}\text { depre } \\
\text { ssion }\end{array}$ & $\begin{array}{l}-.355 \\
* * *\end{array}$ & & -.355 \\
\hline $\begin{array}{l}\text { life- } \\
\text { sustainin } \\
\mathrm{g} \\
\text { treatment } \\
\text { preferenc } \\
\mathrm{e}\end{array}$ & $\begin{array}{l}\square \text { social } \\
\text { support }\end{array}$ & $\begin{array}{c}\square \\
\text { depre } \\
\text { ssion }\end{array}$ & $\begin{array}{c}-.110 \\
*\end{array}$ & $\begin{array}{c}- \\
.058 \\
* *\end{array}$ & -168 \\
\hline
\end{tabular}

주) $* \mathrm{p}<.05, * * \mathrm{p}<.01, * * * \mathrm{p}<.001$

Table 4. The Mediating eddect of ego integrity, social support

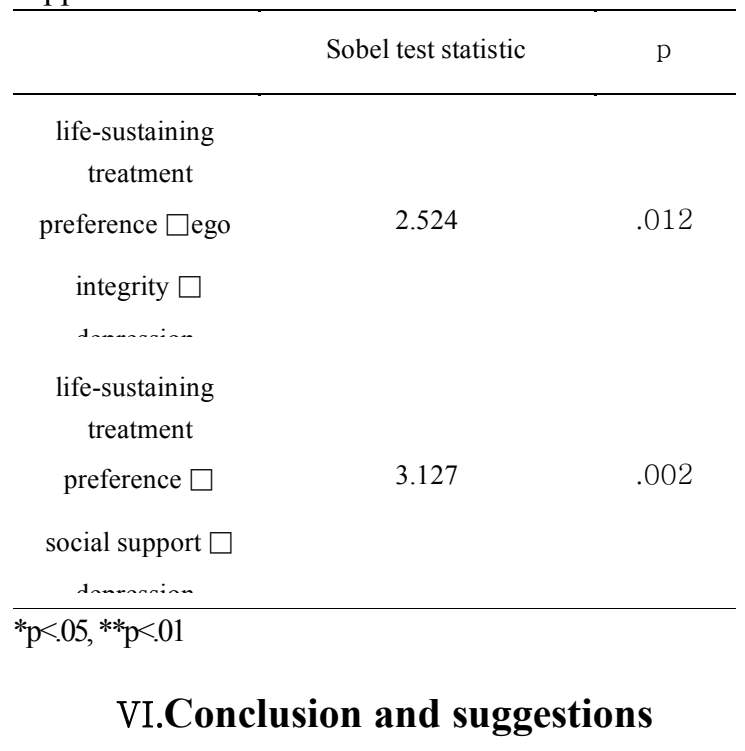

The results of this study showed that ego integrity and social support were very effective variables in suppressing depression of the elderly. According to Kwon[1], the meta-analysis of the variables related to depression suppression of the elderly at home showed that ego integrity, life satisfaction, selfesteem, social support, family support and leisure activities had a great effect as depression suppression variables. In other previous studies, achievement of 
The Effects of Life-sustaining Treatment Preferences on Geriatric Depression: Centered on the Mediating Effects of Ego Integrity and Social Support

ego integrity in old age was explained as a way to overcome depression [2] and social support was predicted to be a very important factor in improving mental health and quality of life by preventing the pathological conversion of depression in the elderly [3]. Thus, ego integrity and social support will become the soil that can meet mature old age, minimizing depression tendency and reducing social problems of the elderly.

Ego integrity and social support were found to be positive factors in the relationship between the elderly's preference for life-sustaining treatment and depression. The elderly with low preference for lifesustaining treatment had a good sense of ego integrity and reduced depression. As such, the degree of preference for life-sustaining treatment and ego integrity, which are the most important points of welldying discussion in old age, was found to be related to depression [4]. In addition, the elderly with low preference for life sustaining treatment showed high social support, and the elderly with high social support showed a decrease in depression. Social support is fully mediated between lifesustaining treatment preference and depression. In other words, in order to reduce the depression of the elderly, it is necessary to guarantee the right to selfdetermination of life-sustaining treatment, and a program to help ego integration is urgently needed. If ego integration is not achieved in old age, the probability of experiencing depression is high. However, if the elderly formed high ego integration and received a lot of informational support and emotional support from family, friends and neighbors, psychological stability that can escape from depression is formed.

It is highly recommended that each senior welfare center and senior centers operate an ego integration program designed to recollect all stages of their past life at senescence and to be able to organize tasks to be achieved on each developmental stage. There is still little research on the preference of life-sustaining treatment in social welfare academia, and the interest in this is very low. Therefore, this study is very useful as there are not many papers on the effects of the elderly's preference for life-sustaining treatment on depression.

I would like to make some suggestions for the limitations and follow-up studies of this study. This study has a limitation that it is difficult to generalize the results of the study due to the representativeness of the sample, and it is limited to the preference of life-sustaining treatment, ego integrity, and social support despite the various factors affecting depression. In the follow-up study, it is hoped that various programs will be developed to change the perception of life-sustaining treatment preference and ego integrity.

\section{References (APA style)}

[1]. Kwon Hyun Sook. A Meta Analysis on Variables Related to Suppression of Depression of In-Home Elderly, Korean Journal of Gerontological Social Welfare. 2013;61: 241-266.

[2]. Chang Sung Ok, Kong Eun Suk, Kim Namho, Kim Chun Gill, Kim Hee Kyung, Song Misoon, An $\mathrm{Su}$ Yen, Lee Young Whee, Cho Nam Ok, Cho Myung Ok, Choi Kyung Sook. A Study of Major Variables Predicting Ego-integrity and Depression in Korean Elders, Korean Gerontol Nurs. 2010; 12(3): 225-236. [3] Tag Yeong Lan, Kim Sun Ae, Lee Bong Sug. Perceived Social Support, Instrumental Support Needs, and Depression of Elderly Women, Korean Society of Women Health Nursing. 2003;19(4): 449456.

[4] Lee Mee Ae. The Effects of Ego Integrity Trait of Elderly Persons on Life-sustaining Treatment Preferences, Journal of Digital Convergence. 2016;14(2):489-499. 